DOI https://doi.org/10.15589/znp2019.1(475).11

УДК 621.438:542.67

\title{
ASSESSMENT OF THE FRACTIONAL EFFICIENCY OF GRADIENT TRANSFER OF AEROSOLS IN ELEMENTS OF POWER PLANTS
}

\author{
ОЦЕНКА ФРАКЦИОННОЙ ЭФФЕКТИВНОСТИ ГРАДИЕНТНОГО \\ ПЕРЕНОСА АЭРОЗОЛЕЙ В ЭЛЕМЕНТАХ ЭНЕРГЕТИЧЕСКИХ УСТАНОВОК
}

\section{ОЦІНКА ФРАКЦИЙНОЇ ЕФЕКТИВНОСТІ ГРАДІЕНТНОГО ПЕРЕНЕСЕННЯ АЕРОЗОЛІВ В ЕЛЕМЕНТАХ ЕНЕРГЕТИЧНИХ УСТАНОВОК}

\author{
Anatolii P. Shevtsov \\ aootnet@ukr.net \\ ORCID: 0000-0002-8692-6458 \\ Heorhii V. Kuznetsov \\ kuznetsov_georgiy@ukr.net \\ ORCID: 0000-0002-1028-4102
}

\author{
А. П. Шевцов, \\ докт. техн. наук, профессор \\ Г. В. Кузнецов, \\ студент
А. П. Шевцов, докт. техн. наук, професор
Г. В. Кузнецов, студент

\section{Admiral Makarov National University of Shipbuilding, Mykolaiv \\ Национальный университет кораблестроения имени адмирала Макарова, г. Николаев Національний університет кораблебудування імені адмірала Макарова, м. Миколаїв}

\begin{abstract}
The article offers the results of the research to develop new generations of gas cleaning devices in power plants and life support systems of the ships. The goal of the research is to determine fractional efficiency of deposition on individual sites of multifunctional surfaces and surfaces in general, the aerosol gradient of resource-saving technologies in ship systems and technical comfort air conditioning. The main research's task is a validated evaluation of fractional efficiency of aerosol transport in the boundary layers multifunctional surfaces in power plants based on the model fractional efficiency of deposition of aerosol particles consistent means as a set of independent events with a constant efficiency. The object of the research is the treatment processes of aerosol environments in power plants and life support systems. Subject of the research is characteristics of a sequence of gradient transfer processes in the boundary layers of multifunctional surfaces during cleaning aerosol environments and their performance fractional efficiency of purification in the ship power plant and life support systems. Research method is probabilistic method of analysis of random processes and assesses the desired level of result with a sequence of events with regard to their inherent elements of randomness. The study substantiates the dependence of the fractional efficiency of deposition of aerosol particles in different variants of gradient transfer in boundary layers multifunctional surfaces. Made interval estimates of the influence of the forces caused by the gradients of the fields of pressure, temperature and concentration on the values of the fractional efficiency of aerosol deposition. Practical value of results consists in proposing a rational method of selecting a sequence of actions of thermal, acoustic and photophoretic effects and the surface tension gradient in aerosol technologies for ship power plant and support life systems.
\end{abstract}

Key words: probability; suppression; particle; boundary layer; multifunctional surface.

Аннотация. В статье поданы результаты исследования для создания новых поколений газоочистительных устройств энергетических установок и систем жизнеобеспечения судов. Целью исследования является определение фракционной эффективности осаждения на отдельных участках многофункциональных поверхностей и поверхности в целом при реализации ресурсосберегающих аэрозольных градиентных технологий в судовых системах технического и комфортного кондиционирования. Основная задача исследования заключается в обосновании достоверности оценки фракционной эффективности переноса аэрозолей в пограничных слоях многофункциональных поверхностей в энергетических установках на основе модели фракционной эффективности осаждения аэрозольной частицы последовательными способами как совокупности независимых событий с постоянной эффективностью. Объектом исследования являются процессы очистки аэрозольных сред в судовых энергетических установках и системах жизнеобеспечения. 
Предметом исследования является характеристика последовательности процессов градиентного переноса аэрозольных сред в пограничных слоях многофункциональных поверхностей и их показателей фракционной эффективности очистки в судовых энергетических установках и системах жизнеобеспечения. Методом исследования является вероятностный метод анализа случайных процессов и оценивания достижения необходимого уровня результата при последовательном проведении событий с учетом присущих им элементов случайности. В результате исследования обоснована зависимость фракционной эффективности осаждения частиц аэрозоля при реализации различных вариантов градиентного переноса в пограничных слоях многофункциональных поверхностей. Предоставлены интервальные оценки влияния действия сил, вызванных градиентами полей давления, температуры и концентраций на значения фракционной эффективности осаждения аэрозолей. Практическая значимость результатов заключается в предложении рационального способа выбора последовательности действий термо-, акустико- и фотофоретических эффектов и сил поверхностного натяжения в аэрозольных градиентных технологиях для судовых энергоустановок и систем жизнеобеспечения.

Ключевые слова: вероятность; осаждение; частица; пограничный слой; многофункциональная поверхность.

Анотація. У статті подано результати дослідження для створення нових поколінь газоочисних пристроїв енергетичних установок і систем життєзабезпечення суден. Метою дослідження є визначення фракційної ефективності осадження на окремих ділянках багатофункціональних поверхонь і поверхні загалом під час реалізації ресурсозберігаючих аерозольних градієнтних технологій у суднових системах технічного та комфортного кондиціонування. Основна задача дослідження полягає в обгрунтуванні достовірності оцінки фракційної ефективності перенесення аерозолів у примежових шарах багатофункціональних поверхонь в енергетичних установках на основі моделі фракційної ефективності осадження аерозольної частинки послідовними способами як сукупності незалежних подій з постійною ефективністю. Об'єктом дослідження є процеси очищення аерозольних середовищ у суднових енергетичних установках і системах життєзабезпечення. Предметом дослідження є характеристики послідовності процесів градієнтного перенесення аерозольних середовищ у примежових шарах багатофункціональних поверхонь та їх показників фракційної ефективності очищення в суднових енергетичних установках і системах життєзабезпечення. Методом дослідження є ймовірнісний метод аналізу випадкових процесів та оцінювання досягнення необхідного рівня результату за послідовного проведення подій з урахуванням властивих їм елементів випадковості. У результаті дослідження обгрунтовано залежність фракційної ефективності осадження частинок аерозолю під час реалізації різних варіантів градієнтного перенесення в примежових шарах багатофункціональних поверхонь. Надано інтервальні оцінки впливу дії сил, викликаних градієнтами полів тиску, температури й концентрацій на значення фракційної ефективності осадження аерозолів. Практична значущість одержаних результатів полягає в пропозиції раціонального способу вибору послідовності дій термо-, акустико- й фотофоретичних ефектів та сил поверхневого натягу в аерозольних градієнтних технологіях для суднових енергоустановок та систем життєзабезпечення.

Ключові слова: ймовірність; осадження; частинка; примежовий шар; багатофункціональна поверхня.

\section{ПОСТАНОВКА ЗАДАЧИ}

Определение фракционной эффективности при очистке аэрозолей в энергетических установках базируется на совместном исследовании газодинамических и тепломассообменных процессов [1-3]. Эти процессы моделируются системой уравнений, полученных на основе законов сохранения импульса, энергии и массы при турбулентном движении многофазного потока с условиями однозначности. Достоверность полученных результатов определяется заданием начальных и граничных условий, которые имеют случайный характер. Это вызывает необходимость дополнительного согласования при субъективном определении краевых условий $[4 ; 5]$.

Альтернативным методом описания физических процессов сепарации в многофазных потоках является определение их вероятностных характеристик [6-8]. Это направление позволяет устранить некоторые недостатки детерминированных моделей про- цессов и использовать вероятностные оценки при их исследовании [9; 10].

\section{АНАЛИЗ ПОСЛЕДНИХ ИССЛЕДОВАНИЙ И ПУБЛИКАЦИЙ}

В работах [6-8] поданы результаты исследования касательно определения эффективности инерционного осаждения жидких и твердых частиц на волокнистых, сетчатых и листовых поверхностях. Показано влияние ориентации в пространстве элементов поверхностей относительно направления движения частиц на эффективность их осаждения. Приводятся зависимости для определения эффективности осаждения и аэродинамического сопротивления в слоях многофункциональных поверхностей и их каналах определенных форм при регулярном их взаимном расположении. При вероятностном оценивании фракционной эффективности в пограничных слоях поверхностей предполагается, что осаждение 
частиц различных размеров осуществляется в том случае, когда на удалении от участка поверхности их начальные координаты находятся на линиях траекторий движения частиц, которые проходят над участком поверхности на расстоянии, которое меньше ее эквивалентного радиуса или равно ему [6]. Поверхности устройств очистки аэрозолей можно представить в виде системы непрерывных (сплошных или прерывистых) волокнистых, сетчатых, пористых элементов различной формы. Классификация схем таких поверхностей представлена в работах [7; 8]. Понятия многофункциональной поверхности, технологических последовательностей процессов очистки, модели многоуровневой системы очистки дисперсных сред для экологических и ресурсосберегающих энергетических установок приведены в работах $[9 ; 10]$. Многофункциональность поверхностей определяется как способность генерировать микровихри для осаждения частиц и отводить осажденные частицы в виде пленок за счет капиллярных сил.

Предложены такие технологические уровни сепарации, как инерционный, градиентный турбофоретический, градиентный неизотермический, градиентный акустикофоретический. В результате этой градации уровней сепарации были учтены такие процессы осаждения частиц: в каналах при обтекании искривленных поверхностей под различными углами атаки системами струй; при обтекании многофункциональных поверхностей в виде систем тонких цилиндров и тонких пластин с выступами на уровне пограничных слоев и отрывных зон.

Научная проблема, на решение которой нацелена работа, заключается в следующем. Реализация очистки многофазных рабочих сред от аэрозолей в энергетических установках требует использования технологий, базирующихся на принципах и методах интенсификации их переноса в пограничных слоях многофункциональных поверхностей при совместном действии сил, вызванных градиентами полей давления, температуры и концентраций. Выявление приоритетности отдельных способов очистки при их совокупном действии и рациональной их последовательности при организации технологии за счет различных форм движения, обмена энергией и массой с использованием внутренних энергоресурсов высокого и низкого потенциалов является научной проблемой создания новых поколений газоочистительных устройств для энергетических установок и систем жизнеобеспечения судов и кораблей.

\section{ВЫДЕЛЕНИЕ НЕ РЕШЕННЫХ РАНЕЕ ЧАСТЕЙ ОБЩЕЙ ПРОБЛЕМЫ}

Влияние формы многофункциональных поверхностей на процессы осаждения определяется размерами аэрозоля, взаимным расположением аэрозоля и поверхности, распределением скорости потока в пограничных слоях, а также температуры и концентрации. Воздействие градиентов давления, температуры и концентрации определяет размеры осаждаемых частиц и их расположение относительно участка поверхности, где они осаждаются. Таким образом, один и тот же участок поверхности характеризуется фракционной эффективностью осаждения частиц для соответствующих распределений скоростей, температур и концентраций. Определение фракционной эффективности осаждения для отдельных участков многофункциональных поверхностей и отыскание закономерностей их изменения вдоль этих поверхностей являются не исследованными ранее частями научной проблемы. Прикладная составляющая этой проблемы требует дополнительного исследования особенностей и закономерностей градиентного переноса фазы в пограничных слоях многофункциональных поверхностей под действием термо-, акустико- и фотофоретичних эффектов и сил поверхностного натяжения в аэрозольных градиентных технологиях для судовых энергоустановок и систем жизнеобеспечения (технического и комфортного кондиционирования включительно).

\section{ЦЕЛЬ ИССЛЕДОВАНИЯ}

Целью статьи является определение фракционной эффективности осаждения на отдельных участках многофункциональных поверхностей и поверхности в целом при реализации ресурсосберегающих аэрозольных градиентных технологий в судовых энергетических установках и системах.

Основная задача исследования заключается в обосновании возможности оценивания фракционной эффективности переноса аэрозолей в пограничных слоях многофункциональных поверхностей в энергетических установках на основе модели фракционной эффективности осаждения аэрозольной частицы последовательными способами как совокупности независимых событий с постоянной эффективностью.

Методы, объект и предмет исследования. Объектом исследования являются процессы очистки аэрозольных сред в судовых энергетических установках и системах жизнеобеспечения. Предметом исследования являются характеристики последовательности процессов градиентного переноса аэрозольных сред в пограничных слоях многофункциональных поверхностей и их показателей фракционной эффективности очистки в судовых энергетических установках и системах жизнеобеспечения. Методом исследования является вероятностный метод анализа случайных процессов и оценивания достижения необходимого уровня результата при последовательном проведении событий с учетом присущих им элементов случайности.

\section{ОСНОВНОЙ МАТЕРИАЛ}

Структура многофункциональных сетчатых поверхностей позволяет предложить такие допущения: 
- $\quad$ при движении частиц аэрозоля, размеры которых соответствуют второму порядку малости по сравнению с размером элемента поверхности, граничные условия одинаковы для всех элементов поверхности и не изменяются вдоль ее пограничных слоев;

- прохождение аэрозольной частицы вдоль поверхности при действии сил, вызванных градиентами полей давления, температуры и концентраций равнозначно проведению серии последовательных независимых испытаний (движение частицы через отдельный элемент поверхности), в результате каждого из которых может с некоторой вероятностью наступить ожидаемое событие, а именно осаждение частицы, причем вероятность осаждения на каждом таком участке постоянная и может быть определена заранее;

- осаждение разных частиц осуществляется независимо одних от других.

С учетом высказанных допущений фракционная эффективность осаждения аэрозоля на всей многофункциональной поверхности определяется таким выражением:

$$
\eta_{\Sigma, d_{s}}=\left[1-\left(1-\eta_{\mathrm{u}, d_{s}}\right)^{m_{\mathrm{u}}} \cdot\left(1-\eta_{\mathrm{T}, d_{s}}\right)^{m_{\mathrm{r}}} \cdot\left(1-\eta_{\mathrm{H}, d_{s}}\right)^{m_{\mathrm{u}}} \cdot\left(1-\eta_{\mathrm{a}, d_{s}}\right)^{m_{\mathrm{a}}}\right],
$$

где $\eta$ - вероятность осаждения частицы на элемент поверхности; $m$ - количество последовательных

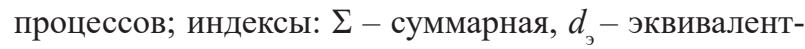
ный диаметр частицы, и - инерционная, т - турбулентная, н - неизотермичная, а - акустическая.

Согласно источникам $[9 ; 10]$ инерционная составляющая вероятности осаждения частицы может быть определена для сухого элемента поверхности таким образом:

$$
\eta_{i}=1-\left[1-e^{n_{x} d_{\mathrm{B}}-1}\left(1-e^{-n_{y} y_{0}}\right)\right]^{c^{\prime} n_{x}},
$$

а смоченого элемента поверхности может быть определена таким образом:

$$
\eta_{i}^{*}=1-\left[1-e^{n_{x} d_{\mathrm{B}}+n_{x}{ }^{2}{ }^{\prime}{ }_{\mathrm{nn}}-1}\left(1-e^{-n_{y} y_{0}}\right)\right]^{\mathrm{c}^{\prime} n_{x}},
$$

где $n_{x}, n_{y}$ - среднее количество волокон на единицу длины вдоль осей $X$ и $Y$ соответственно; $d_{\text {в }}$ - диаметр волокна сетки; $\delta_{\text {пл }}, \delta_{\text {сл }}$ - толщины пленки и слоя соответственно; $y_{0}$ - координата частиц аэрозоля.

При инерционном, градиентном турбофоретическом, градиентном неизотермическом, градиентном акустикофоретическом технологических уровнях сепарации траектория движения частицы изменяется, как показано на рис. 1. В результате этого значение величины $y_{0}$ увеличивается до значения $y_{0 \Sigma}$, где:

$$
y_{0 \Sigma}=y_{0}+y_{\mathrm{T}}+y_{\mathrm{H}}+y_{\mathrm{a}} \text {. }
$$

Тогда фракционная эффективность осаждения аэрозоля на всей многофункциональной поверхности определяется такими выражениями:

$$
\begin{gathered}
\eta_{i}=1-\left[1-e^{n_{x} d_{\mathrm{B}}-1}\left(1-e^{-n_{y} y_{0} \Sigma}\right)\right]^{\mathrm{c}^{\mathrm{c}} n_{x}} ; \\
\eta_{i}^{*}=1-\left[1-e^{n_{x} d_{\mathrm{B}}+n_{x} 2^{\prime}{ }_{\mathrm{m}}-1}\left(1-e^{-n_{y} y_{0 \Sigma}}\right)\right]^{\mathrm{c}^{\mathrm{c} n} n_{x}} .
\end{gathered}
$$

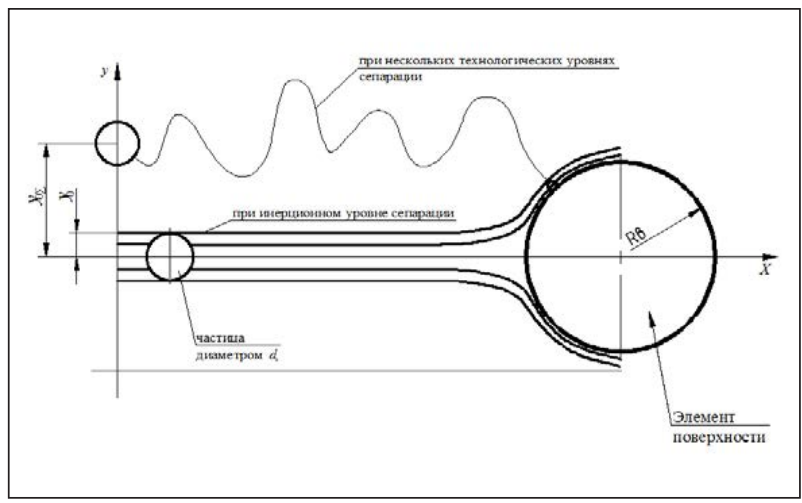

Рис. 1. Схема влияния сил на траекторию движения частицы при нескольких технологических уровнях сепарации

Зависимости фракционной эффективности осаждения аэрозоля на многофункциональной сетчатой поверхности исследовались поэтапно для трех сеток № 05, 016, 0056 [11] с диаметром волокон 0,25; 0,10 и 0,04 мм. На первом этапе исследовалась инерционная эффективность осаждения $\eta_{\text {н,dэ }}$ одиночного аэрозоля размером, соответствующем эквивалентно-

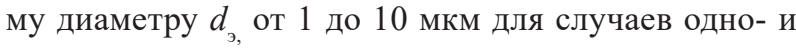
многорядного последовательного расположения волокон сетки. Значения координаты частиц аэрозоля $y_{0 \Sigma}$ принимались из условия равномерного их расположения в пространстве при заданных концентрации и размеров. С увеличением объемной концентрации аэрозоля увеличиваются их поверхностная и линейная концентрации, в результате чего уменьшается координата частиц аэрозоля $y_{0}$ относительно волокна сетки. Результаты полученных оценок представлены на рис. 2. Они подтверждают, что с увеличением размера аэрозольной частицы и количества рядов волокон вдоль ее движения вероятность осаждения возрастает. Начальная концентрация аэрозоля задавалась в диапазоне 0,002-0,57 г воды/кг воздуха, который соответствует условиям для элементов энергетических установок водоизмещающих судов при силе ветра от 0 до 8 балов.

На втором этапе исследовалась инерционная эффективность осаждения аэрозольных потоков для различных начальных концентраций аэрозоля в диапазоне от 0,002 до 50 г/кг, который соответствует условиям для элементов энергетических установок водоизмещающих судов, на подводных крыльях и воздушной подушке, а также случаев однои многорядного последовательного расположения листов плоской и гофрированной сетки. Результаты полученных оценок представлены на рис. 3-5. 


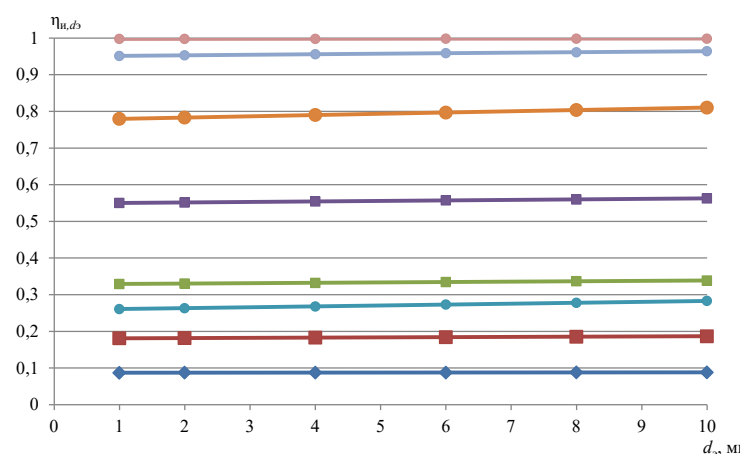

Рис. 2. Зависимость инерционной эффективности осаждения одиночного аэрозоля для случаев одно- и многорядного последовательного расположения волокон сетки при $\mathrm{y}_{0}=5 \cdot 10^{-3}$ мм: сетка 05 с толщиной слоя - 20 мм; сетка 016 с толщиной слоя -5 мм, - 10 мм, - 20 мм; сетки 0056 с толщиной слоя -1 мм, - -5 мм, $\bullet-10 \mathrm{MM}, \bullet-20 \mathrm{Mм}$

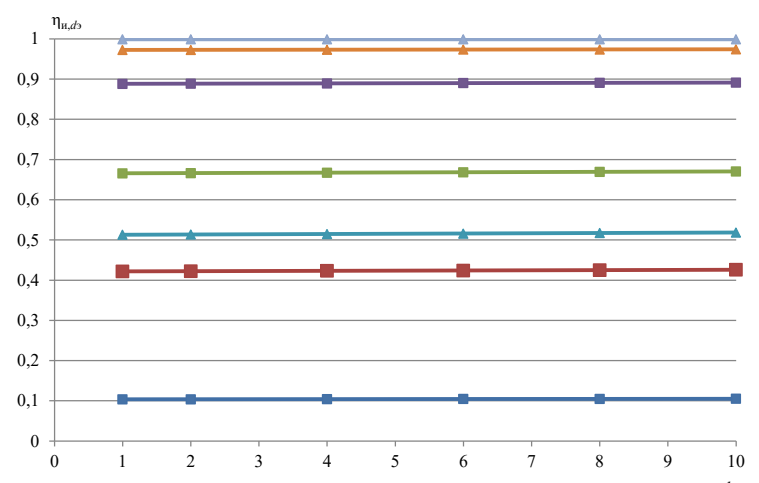

Рис. 3. Зависимость эффективности осаджений в сетке 05 аэрозольных потоков с концентрацией, соответствующей $\mathrm{y}_{01}=125 \cdot 10^{-3}$ мм с толщиной слоя - $-1 \mathrm{Mм},-5 \mathrm{Mм},-10$ мM, - -20 мм и $\mathrm{y}_{02}=125 \cdot 10^{-2}$ мм с толщиной слоя $\boldsymbol{\Delta}-1$ мм, $\Delta-5 \mathrm{MM}, \triangle-10 \mathrm{MM}$

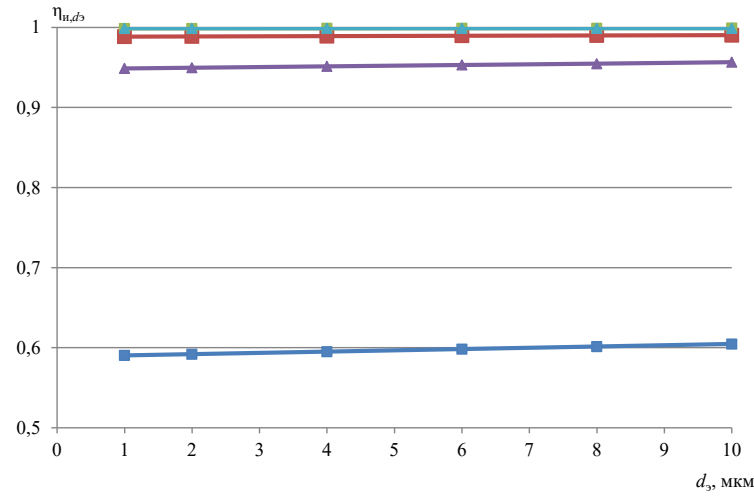

Рис. 4. Зависимость эффективности осаждений в сетке 016 аэрозольныхпотоков сонцентрацией, соответствующей $\mathrm{y}_{01}=125 \cdot 10^{-3}$ мм; обозначения соответствуют рис. 3

С увеличением концентрации инерционная эффективность осаждения увеличивается, а при многорядном расположении сеток в многофункциональной поверхности вероятность осаждения возрастает до значений, которые приемлемы для элементов энергетических установок.

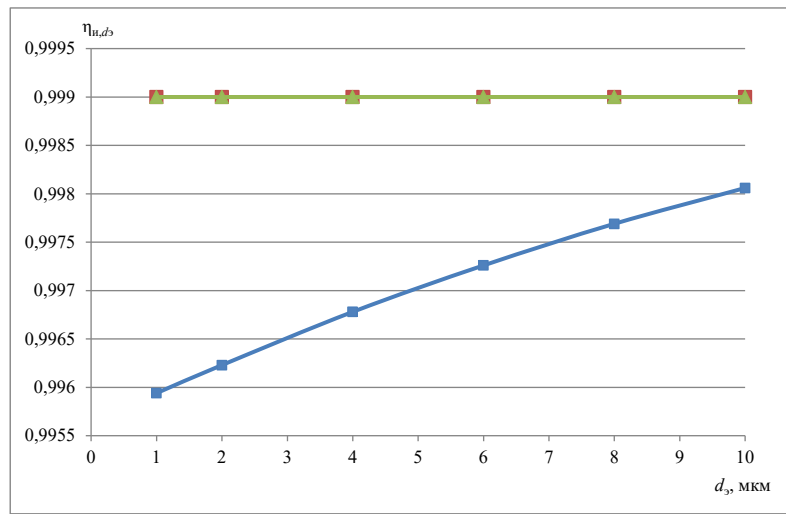

Рис. 5. Зависимость эффективности осаждений в сетке 0056 аэрозольных потоков с концентрацией, соответствующей $\mathrm{y}_{01}=125 \cdot 10^{-3}$ мм; обозначения соответствуют рис. 3

Последующее увеличение эффективности осаждения при многорядном расположении сеток в многофункциональной поверхности является возможным при последовательном или одновременном применении нескольких технологических уровней сепарации, поэтому на третьем этапе исследовалась эффективность осаждения аэрозольных потоков при одновременном применении нескольких технологических уровней сепарации для различных начальных концентраций аэрозоля и случаев многорядного последовательного расположения листов плоской и гофрированной сетки. Достижение фракционной эффективности осаждения аэрозоля на всей многофункциональной поверхности на уровне 0,99-0,999 является возможным при сочетании нескольких вариантов технологических уровней сепарации с различным распределением в суммарной эффективности осаждения аэрозоля инерционной, турбулентной, неизотермичной и акустической составляющих сепарации. На основании обработки экспериментальных данных разных технологических уровней сепарации можно составить такую систему уравнений для определения инерционной, турбулентной, неизотермичной и акустической составляющих сепарации:

$$
\begin{gathered}
\eta_{\Sigma, d_{9}}=\left[1-\left(1-\eta_{\text {и, } d_{9}}\right) \cdot\left(1-\eta_{\mathrm{T}, d_{9}}\right) \cdot\left(1-\eta_{\mathrm{H}, d_{9}}\right) \cdot\left(1-\eta_{\mathrm{a}, d_{9}}\right)\right] ; \\
\eta_{\text {итн }, d_{9}}=\left[1-\left(1-\eta_{\mathrm{u}, d_{9}}\right) \cdot\left(1-\eta_{\mathrm{T}, d_{9}}\right) \cdot\left(1-\eta_{\mathrm{H}, d_{9}}\right)\right] ; \\
\eta_{\text {ит, }, d_{9}}=\left[1-\left(1-\eta_{\mathrm{u}, d_{9}}\right) \cdot\left(1-\eta_{\mathrm{T}, d_{9}}\right)\right] ; \\
\eta_{\mathrm{u}, d_{9}}=F\left(\mathrm{n}_{x}, \mathrm{n}_{\mathrm{y}}, d_{\mathrm{B}}, \delta_{\text {плл }}, \delta_{\text {слл }}, y_{0}\right),
\end{gathered}
$$

где $\eta_{\Sigma, d \ni} ; \eta_{\text {итн,dэ} ;} ; \eta_{\text {ит,dэ }}$ - заданные значения эффективности вариантов технологических уровней сепарации.

Результаты распределения в суммарной эффективности осаждения аэрозоля $\eta_{\Sigma, d \vartheta}=0,999$ инерционной, 
ТЕПЛОЕНЕРГЕТИКА №1 2019

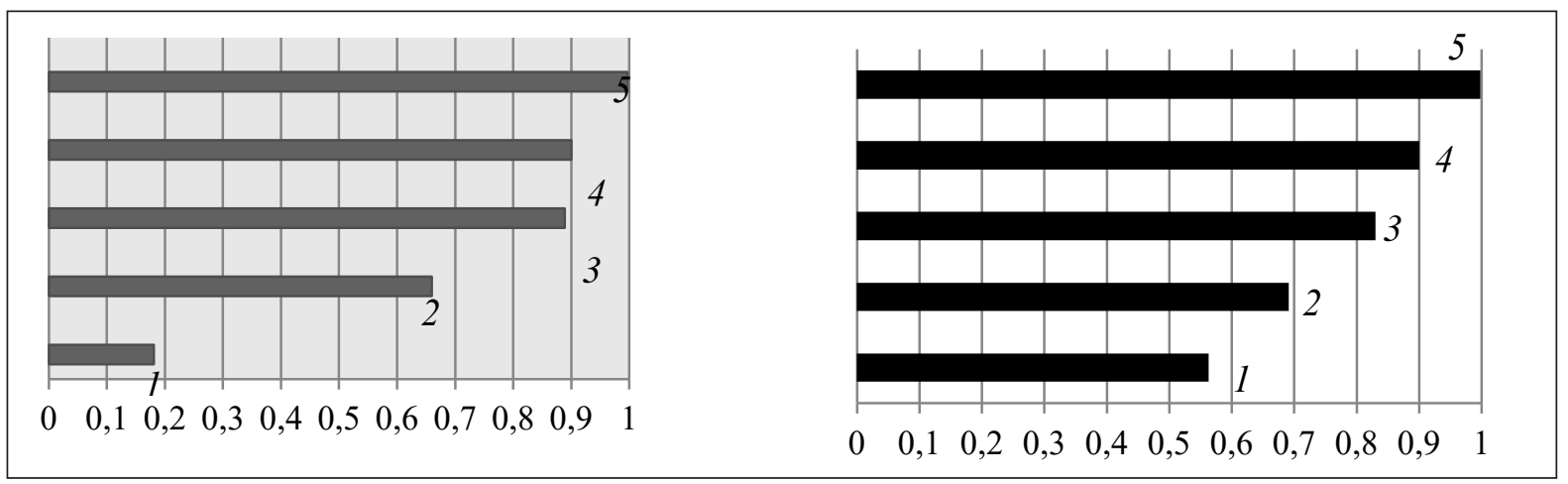

a)

б)

Рис. 6. Распределение эффективности осаждения для двух вариантов: а) однослойной; б) двадцатислойной мнофункциональных поверхностей; $1-\eta_{\text {и, }}-$ инерционная вероятность осаждения частицы на элемент поверхности; $2-\eta_{\mathrm{T}, \mathrm{d}}-$ турбулентная; $3-\eta_{\mathrm{H}, \mathrm{d} э}-$ неизотермичная; $4-\eta_{\mathrm{a}, \mathrm{d} э}-$ акустическая; $5-\eta_{\Sigma, \mathrm{d \jmath}}-$ суммарная

турбулентной, неизотермичной и акустической составляющих сепарации для двух вариантов многофункциональной поверхности представлены на рис. 6 .

\section{ОБСУЖДЕНИЕ ПОЛУЧЕННЫХ РЕЗУЛЬТАТОВ}

Как следует из представленных распределений, заданная суммарная эффективность осаждения аэрозоля $\eta_{\Sigma, d э}=0,999$ может быть достигнута при реализации нескольких вариантов сочетаний инерционного, градиентного турбофоретического, градиентного неизотермического и градиентного акустикофоретического технологических уровней. Выбор более рационального варианта в этом случае должен выполняться на основе дополнительных технико-экономических и массогабаритных критериев элементов и энергетической установки в целом.

\section{ВЫВОДЫ}

На основе проведенного исследования можно сделать такие выводы.
1) Обоснована возможность оценивания фракционной эффективности переноса аэрозолей в пограничных слоях многофункциональных поверхностей в энергетических установках на основе модели фракционной эффективности осаждения аэрозольных частиц последовательными способами как совокупности независимых событий с постоянной эффективностью.

2) Приведенные результаты позволяют выбрать материал сетки по исходным данным суммарной фракционной эффективности, размера аэрозоля и последовательности процессов инерционной, турбулентной, неизотермичной и акустической составляющих сепарации.

3) Выбор рационального варианта многофункциональных поверхностей при реализации ресурсосберегающих аэрозольных градиентных технологий в судовых энергетических установках и системах должен выполняться на основе дополнительных технико-экономических и массогабаритных критериев ее элементов и энергетической установки в целом.

\section{REFERENCES}

[1] Basok, B. I., \& Ryzhkov, S. S. (2003). Termoforeticheskaya ochistka vozdukha v energeticheskom oborudovanii [Thermophoretic air purification in power equipment]. Promyshlennaya teplotekhnika [Industrial heat engineering], 5, 45-50 (in Russian).

[2] Ryzhkov, S. S. (2010). Issledovaniya gazodinamiki i teploperenosa turbulentnykh gazovykh sred s pomoshchyu golograficheskoy interferometrii [Gas dynamics and heat transfer studies of turbulent gaseous media using holographic interferometry]. Visnyk Natsionalnoho universytetu korablebuduvannya [Bulletin of the National University of shipbuilding], 4 (in Russian).

[3] Ryzhkov, S. S. (2014). Uzahalnena matematychna model vyznachennia intensyvnosti protsesu ochystky dyspersnykh bahatofaznykh potokiv u systemakh enerhetychnykh ustanovok [Generalized mathematical model for determining the intensity of the process of purification of dispersed multiphase flows in power plant systems]. Zbirnyk naukovykh prats NUK [Collection of scientific works of NUS], 3, 69-76 (in Ukrainian).

[4] Ryzhkov, S. S. (2014). Problemy intensyfikatsii ochystky v bahatofaznykh dyspersnykh seredovyshchakh enerhetychnykh ustanovok i sposoby yikh vyrishennia. Ch. 1 [Problems of purification intensification in multiphase dispersed media of power plants and methods for their solution. Part 1]. Zbirnyk naukovykh prats NUK [Collection of scientific works of NUS], 5, 51-58 (in Ukrainian).

[5] Ryzhkov, S. S. (2014). Problemy intensyfikatsii ochystky v bahatofaznykh dyspersnykh seredovyshchakh enerhetychnykh ustanovok i sposoby yikh vyrishennia. Ch. 2 [Problems of purification intensification in multiphase dispersed media of power plants and methods for solving them. Part 2]. Zbirnyk naukovykh prats NUK [Collection of scientific works of NUS], 6, 51-57 (in Ukrainian). 
[6] Shevtsov, A. P., Vasilev, A. G., \& Kafka, Ye. A. (1985). Metodika veroyatnostnoy otsenki effektivnosti voloknistykh filtrov [The method of probabilistic assessment of the effectiveness of fiber filters]. Teploenergetika i khladotekhnika: sb. nauch. tr. [Thermal Engineering and Refrigeration: A Collection of Scientific Papers], 58-63 (in Russian).

[7] Shevtsov, A. P., \& Kozinets, S. A. (1989). Osazhdenie zhidkosti v elementakh matrits kontaktnykh teplomassoobmennykh apparatov [Liquid deposition in the elements of contact heat and mass transfer apparatus matrices]. Sudovye energeticheskie ustanovki: sb. nauch. tr. [Marine power plants: collection of scientific papers], 66-73 (in Russian).

[8] Shevtsov, A. P., \& Kozinets, S. A. (1990). Osazhdenie kapel zhidkosti v kanalakh matrits kontaktnykh teplomassoobmennykh apparatov [Precipitation of liquid droplets in the channels of the contact matrices of heat and mass transfer apparatus]. Sudovoe energomashinostroenie: sb. nauch. tr. [Ship power engineering: a collection of scientific papers], 84-95 (in Russian).

[9] Ryzhkov, S. S., \& Goncharova, N. A. (2010). Intensifikatsiya osazhdeniya zhidkikh chastits za schet poperechnykh pulsatsiy setok gofrirovannogo koagulyatora [Intensification of liquid particle deposition due to transverse pulsations of corrugated coagulator meshes]. Visnyk Natsionalnoho universytetu korablebuduvannya [Bulletin of the National University of shipbuilding], 1. Retrieved from: http://evn.nuos.edu.ua (in Russian).

[10] Ryzhkov, S. S. (2016). Osazhdenie aerozoley v pogranichnykh sloyakh ploskikh poverkhnostey energeticheskikh ustanovok [Aerosol deposition in the boundary layers of flat surfaces of power plants]. Zbirnyk naukovykh prats NUK [Collection of scientific works of NUS], 4, 53-60 (in Russian).

[11] GOST 6613-86 (1986). Setki provolochnyye tkanyye s kvadratnymi yacheykami. Tekhnicheskiye usloviya [Woven wire mesh with square cells. Technical conditions] (n. d.) (in Russian).

\section{СПИСОК ИСПОЛЬЗОВАННОЙ ЛИТЕРАТУРЫ}

[1] Басок Б.И., Рыжков С.С. Термофоретическая очистка воздуха в энергетическом оборудовании. Промышленная теплотехника. 2003. № 5. С. 45-50.

[2] Рыжков С.С. Исследования газодинамики и теплопереноса турбулентных газовых сред с помощью голографической интерферометрии. Вісник НУК. 2010. № 4.

[3] Рижков С.С. Узагальнена математична модель визначення інтенсивності процесу очистки дисперсних багатофазних потоків у системах енергетичних установок. Збірник наукових пращь НУК. 2014. № 3. С. 69-76.

[4] Рижков С.С. Проблеми інтенсифікації очистки в багатофазних дисперсних середовищах енергетичних установок i способи їх вирішення. Частина 1. Збірник наукових пращьь НУК. 2014. № 5. С. 51-58.

[5] Рижков С.С. Проблеми інтенсифікації очистки в багатофазних дисперсних середовищах енергетичних установок $\mathrm{i}$ способи їх вирішення. Частина 2. Збірник наукових пращъь НУК. 2014. № 6. С. 51-57.

[6] Шевцов А.П., Васильев А.Г., Кафка Е.А. Методика вероятностной оценки эффективности волокнистых фильтров. Теплоэнергетика и хладотехника : сборник научных трудов. 1985. С. 58-63.

[7] Шевцов А.П., Козинец С.А. Осаждение жидкости в элементах матриц контактных тепломассообменных аппаратов. Судовые энергетические установки : сборник научных трудов. 1989. С. 66-73.

[8] Шевцов А.П., Козинец С.А. Осаждение капель жидкости в каналах матриц контактных тепломассообменных аппаратов. Судовое энергомашиностроение : сборник научных трудов. 1990. С. 84-95.

[9] Рыжков С.С., Гончарова Н.А. Интенсификация осаждения жидких частиц за счет поперечных пульсаций сеток гофрированного коагулятора. Вісник НУК. 2010. № 1. URL: http://evn.nuos.edu.ua.

[10] Рыжков С.С. Осаждение аэрозолей в пограничных слоях плоских поверхностей энергетических установок. Збірник наукових праць НУК. 2016. № 4. С. 53-60.

[11] ГОСТ 6613-86. Сетки проволочные тканые с квадратными ячейками. Технические условия. 1986 (n. d.). 